\title{
Características mineralógicas de latossolos e argissolos na região sul do Amazonas
}

\author{
Mineralogical characteristics of oxisols and ultisols in Southern Amazonas
}

Milton César Costa Campos ${ }^{[a]}$, Mateus Rosas Ribeiro ${ }^{[b]}$,Valdomiro Severino de Souza Júnior ${ }^{[c]}$, Mateus Rosas Ribeiro Filho ${ }^{[c]}$, Rômulo Vinícius Cordeiro Conceição de Souza[d], Maria da Conceição de Almeida ${ }^{[d]}$

[a] Engenheiro agrônomo, Doutor, professor adjunto do Instituto de Educação, Agricultura e Ambiente da Universidade Federal do Amazonas, Humaitá, AM - Brasil, e-mail: agromccc@yahoo.com.br; mcesarsolos@ufam.edu.br

[b] Engenheiro agrônomo, PhD, professor associado da Universidade Federal Rural de Pernambuco, Recife, PE -Brasil, e-mail: mrosas@depa.ufrpe.br

[c] Engenheiro agrônomo, Doutor, professor adjunto da Universidade Federal Rural de Pernambuco, Recife, PE -Brasil, e-mail: vsouzajr@yahoo.com; mateusrf@depa.ufrpe.br

[d] Engenheiros agrônomos, doutorandos em Agronomia (Ciência do Solo) da Universidade Federal Rural de Pernambuco, Recife, PE - Brasil, e-mail: rvccsouza@yahoo.com.br; marycalmeida07@hotmail.com

\section{Resumo}

O objetivo deste estudo foi caracterizar latossolos e argissolos na região sul do Amazonas. Foram selecionados oito locais de amostragem, sendo quatro sob sítios de terras pretas arqueológicas (P1, P2, P3 e P4) e quatro sob os seguintes segmentos de vertente: topo alto (P5), encosta (P6), sopé de transporte (P7) e topo baixo (P8). Em seguida, foram abertas trincheiras nesses locais e os perfis foram caracterizados morfologicamente e coletados por horizontes para realização das análises. Foram realizadas análises mineralógicas (frações areia, silte e argila) usando difratometria de raios X. Todos os perfis estudados apresentaram mineralogia semelhante das frações areia, silte e argila, com destaque para a fração argila que apresentou picos mais expressivos de caulinita e gibbsita.

Palavras-chave: Mineralogia. Amazônia. Solos e pedogênese.

\section{Abstract}

The objective of this study was to characterize oxisols and ultisols in southern Amazonas. We selected eight sampling locations, four sites in archaeological black earth (P1, P2, P3 and P4) and four under the following segments of the head: high-topped (P5), slope (P6), foothills of transport (P7) bottom-topped (P8). Then trenches were opened in these locations mapped and the profiles were characterized morphologically and collected by horizons for the analysis. Mineralogical analyses were conducted using X-ray diffraction. All studied profiles presented similar mineralogy of sand, silt and clay, especially for the clay fraction which showed quite significant peaks of kaolinite and gibbsite.

Keywords: Mineralogy. Amazon. Soils and pedogenesis. 


\section{Introdução}

A região sul do Amazonas ocupa aproximadamente $12 \%$ da área total do Estado, com aproximadamente $177.526,80 \mathrm{~km}^{2}$, abrangendo os municípios de Humaitá, Manicoré, Apuí e Novo Aripuanã. De forma genérica, essa região apresenta três diferentes fisiografias: várzea/terra firme, campo/ floresta e áreas de relevo movimentado. A região coberta por campo/floresta, segundo Martins et al. (2006), é uma parte da região sul do Amazonas que caracteriza-se pela presença de campos não contínuos, ou seja, várias unidades isoladas entremeadas por floresta, refletindo as condições dos solos em cada ambiente fisiográfico. Outra boa parte dessa região é formada pelos ecossistemas de várzeas e terra firme, o que reflete os diferentes ambientes edáficos e favorece a adaptação da vegetação às condições de inundação sazonal ou não (GAMA et al., 2005).

De maneira geral, a variação dos solos reflete em grande parte as características do material de origem, sendo, também, influenciada por outros fatores, como as condições bioclimáticas e o relevo. $\mathrm{Na}$ região amazônica essas condições não se apresentam diferentes, sendo incrementadas por outros fatores, tais como: nível elevado do lençol freático, inundações periódicas e arraste de sedimentos pelas águas, o que limita a evolução pedogenética (LIMA, 2001), ocasionando, assim, a presença de solos jovens e, em alguns casos, sedimentos em processo incipiente de pedogênese.

Além disso, a Floresta Amazônica ainda guarda algumas peculiaridades, como é o caso das Terras Pretas Arqueológicas (TPAs) ou de Índio, que são classes de solos cuja característica marcante é a coloração escura e a presença de fragmentos de cerâmica e/ou líticos e artefatos indígenas incorporados à matriz dos horizontes superficiais do solo (KAMPF; KERN, 2005). De acordo com Glaser (2007), esses solos normalmente apresentam elevada fertilidade natural, com altos teores de $\mathrm{P}, \mathrm{Ca}$, Mg e matéria orgânica estável, além de intensa atividade biológica quando comparados aos solos adjacentes. A formação desses solos ainda não é bem explicada, mas a hipótese mais aceita se baseia em evidências pedológicas e arqueológicas de que as Terras Pretas Arqueológicas teriam sido formadas não intencionalmente pelo homem pré-colombiano (KAMPF; KERN, 1989).
Apesar dessa diversidade de ambiente nessa região, poucos estudos preocuparam-se em estudar as relações mineralógicas dos diversos ambientes fisiográficos presentes na região sul do Amazonas. Sendo assim, o objetivo deste trabalho foi estudar as características mineralógicas de latossolos e argissolos na região sul do Amazonas.

\section{Materiais e métodos}

As áreas de estudo localizaram-se ao sul do Estado do Amazonas, nas imediações da comunidade Santo Antônio de Matupi, às margens da BR 319, Rodovia Transamazônica, município de Manicoré. As coordenadas geográficas são $07^{\circ} 59^{\prime} 77,1^{\prime \prime} \mathrm{S}$ e $61^{\circ} 39^{\prime} 51,2^{\prime \prime} \mathrm{W}$, com altitude média variando entre 60 e 150 metros acima do nível do mar.

0 material de origem é proveniente do saprolito de granitos rondonianos do pré-cambriano superior, sedimentos coluviais, depositados nas partes mais baixas da paisagem e coberturas terciárias (BRASIL, 1978). 0 clima da região, segundo a classificação de Köppen, é do tipo tropical chuvoso, apresentando um período seco de pequena duração $(\mathrm{Am})$, com temperaturas variando entre $25^{\circ} \mathrm{C}$ e $27^{\circ} \mathrm{C}$, e com precipitações pluviométricas entre 2.250 e 2.750 $\mathrm{mm}$, com chuvas concentradas no período de outubro a junho.

A configuração do relevo é marcada pela presença de platôs que exibem superfícies planas, sendo a zona de borda marcada por colinas e cristas alinhadas e localmente escarpadas, enquanto as áreas planas têm, como principal característica, a presença de uma superfície pediplanada (CPRM, 2001). A vegetação característica dessa região é a Floresta Tropical Densa, constituída por árvores adensadas e multiestratificadas, entre 20 e 50 metros de altura (ZEE-AM, 2008).

Foram selecionados quatro locais situados em posições distintas da paisagem, porém sob sítios de Terras Pretas Arqueológicas (Figura 1). Os perfis P1 e P3 localizam-se em posições de topo, sendo o P1 sob vegetação secundária (capoeira) e o P3 sob vegetação primária de floresta densa. 0 perfil P2 localiza-se no sopé da vertente, sob formação secundária de capoeira, e o $\mathrm{P} 4$, em posição de meia encosta, sob vegetação recentemente desmatada e queimada para implantação de pastagem. 


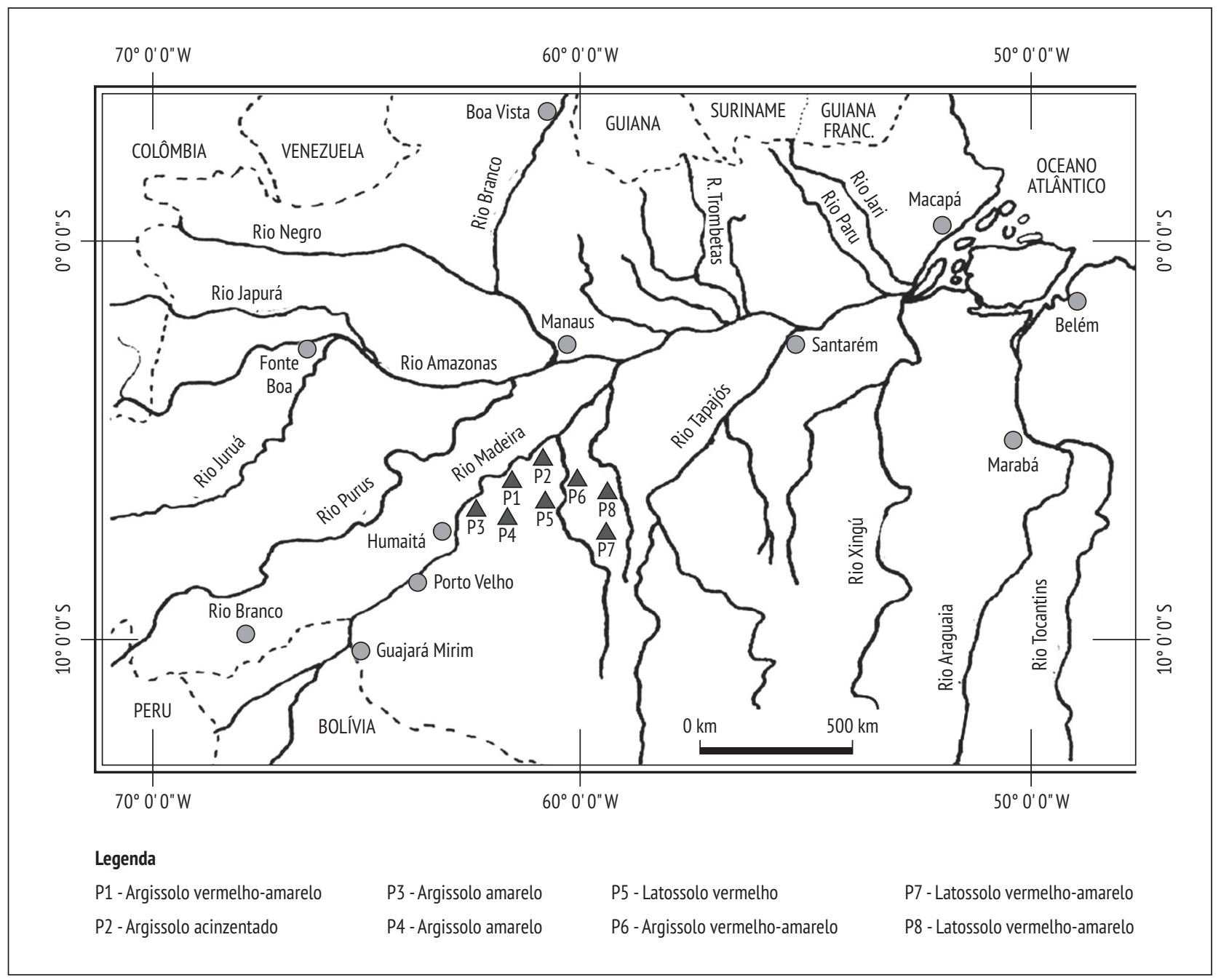

Figura 1 - Mapa com a localização dos perfis estudados na região do Médio Rio Madeira, Amazonas Fonte: Dados da pesquisa.

Outros quatro locais foram escolhidos seguindo o "espigão" da vertente no sentido do caimento mais suave do declive, partindo-se do topo até a área de sopé. Com base no modelo de Dalrymple et al. (1968), foram reconhecidos os seguintes segmentos de vertente: topo alto (P5), encosta (P6), sopé de transporte (P7) e topo baixo (P8) (Figura 1). 0 reconhecimento baseou-se principalmente na declividade do terreno, direcionado pela transeção escolhida, cuja finalidade foi estabelecer relações entre as unidades de vertente.

Nesses locais foram abertas trincheiras e os perfis foram caracterizados morfologicamente e coletados por horizontes, segundo Santos et al. (2005). Nas amostras assim coletadas foram realizadas análises físicas, químicas e mineralógicas. Em seguida, os solos foram classificados segundo critérios estabelecidos pelo SiBCS (EMBRAPA, 2006).

Após as extrações das frações areia, silte e argila, a identificação dos minerais foi feita por difratometria de raios X (DRX). Os difratogramas foram obtidos empregando-se difratômetro Shimadzu, operando a uma tensão de 40 volts, com corrente de $20 \mathrm{~mA}$, radiação de Cuk $\alpha$, com monocromador de grafite. A amplitude de varredura foi de 5 a $70^{\circ}(2 \theta)$ e uma velocidade de registro de $3^{\circ} 2 \theta \mathrm{min}^{-1}$ para areia e silte; amplitude de 3 a $70^{\circ}(2 \theta)$ e mesma velocidade para a argila pó. Para as amostras saturadas com $\mathrm{KCl}$ (temperatura ambiente e aquecidas a $550{ }^{\circ} \mathrm{C}$ ) e saturadas com $\mathrm{MgCl}_{2}$ com posterior solvatação com glicerol, a amplitude de varredura foi de 3 a $35^{\circ}(2 \theta)$ e uma velocidade de registro de $2^{\circ} 2 \theta \mathrm{min}^{-1}$. 


\section{Resultados e discussão}

A mineralogia da fração areia das Terras Pretas Arqueológicas (P1, P2, P3 e P4) é apresentada na Tabela 1. Verificou-se que os perfis P2 e P3 apresentaram comportamento semelhante, com presença de caulinita, quartzo e feldspatos no horizonte $A_{1}$, enquanto no horizonte Bt foram observados, além dos acima citados, gibbsita, anatásio e ilmenita.

Para os perfis $\mathrm{P} 1$ e $\mathrm{P} 4$ observou-se a presença de caulinita e quartzo associada à presença de óxidos e hidróxidos de ferro e alumínio, tais como goethita e gibbsita, no horizonte superficial, enquanto nos horizontes subsuperficiais foi constatada, além dos minerais acima citados, a presença de feldspatos e $\mathrm{Gt}+\mathrm{Hm}$ para o $\mathrm{Bt}_{1}$ do $\mathrm{P} 1$.

A composição mineralógica da fração silte mostrou-se bastante semelhante, com presença marcante de quartzo, gibbsita e anatásio, e menores reflexos de caulinita, goethita, feldspatos e ilmenita. Essa composição mineralógica dos solos reflete, de certo modo, a pobreza do material de origem (granitos e sedimentos terciários) (BRASIL, 1978), associada ao intenso intemperismo químico que predomina na região amazônica.

Tabela 1 - Composição mineralógica das frações areia e silte dos horizontes diagnósticos superficiais e subsuperficiais dos perfis de Terras Pretas Arqueológicas na região do Médio Rio Madeira, AM

\begin{tabular}{|c|c|c|c|}
\hline Horizonte & Profundidade (cm) & Areia & Silte \\
\hline \multicolumn{4}{|c|}{ P1 - Argissolo vermelho-amarelo eutrófico abrúptico } \\
\hline$A_{1}$ & $0-19$ & $\mathrm{~K}, \mathrm{~Gb}, 0$ e Gh & Q, An, Fd e Im \\
\hline $\mathrm{Bt}_{1}$ & $37-70$ & $\mathrm{~K}, \mathrm{~Gb}, \mathrm{O}, \mathrm{Gh}, \mathrm{Hm}$ e Fd & Q, An, Fd e Im \\
\hline \multicolumn{4}{|c|}{ P2 - Argissolo acinzentado eutrófico típico, textura média (leve)/argilosa } \\
\hline$A_{1}$ & $0-32$ & $\mathrm{~K}, \mathrm{Q}$ e Fd & $0, A n, F d$ e Im \\
\hline Bt & $75-105$ & $\mathrm{~K}, \mathrm{Q}$ e Fd & Q, An, Fd e Im \\
\hline \multicolumn{4}{|c|}{ P3 - Argissolo amarelo eutrófico abrúptico } \\
\hline$A_{1}$ & $0-20$ & $\mathrm{~K}, \mathrm{~Gb}, \mathrm{Q}, \mathrm{An}, \mathrm{Fd}$ e Im & Q,An, Fd e Im \\
\hline $\mathrm{Bt}_{1}$ & $70-110$ & $\mathrm{~K}, \mathrm{~Gb}, \mathrm{Q}, \mathrm{An}, \mathrm{Fd}$ e Im & Q,An, Fd e Im \\
\hline \multicolumn{4}{|c|}{ P4 - Argissolo amarelo eutrófico típico } \\
\hline$A_{1}$ & $0-20$ & $\mathrm{~K}, \mathrm{~Gb}, \mathrm{O}, \mathrm{Gh}, \mathrm{An}$, e Im & Q,An, e Im \\
\hline $\mathrm{Bt}_{1}$ & $108-153$ & K, Gb, O, Gh, An, Fd e Im & Q,An, Fd e Im \\
\hline
\end{tabular}

Legenda: $\mathrm{Q}$ = quartzo; $\mathrm{Gb}$ = gibbsita; $\mathrm{K}$ = caulinita; $\mathrm{Hm}$ = hematita; $\mathrm{Gh}=$ goethita; $\mathrm{An}=$ anatásio; $\mathrm{Im}$ = ilmenita; $\mathrm{Fd}$ = feldspatos; $\mathrm{M}$ = mica.

Fonte: Dados da pesquisa.

A mineralogia da fração argila das TPAs foi semelhante, com dominância nítida de caulinita e gibbsita, além de traços de mica e goethita (Figuras 2, 3, 4 e 5), não diferindo dos resultados encontrados por Couceiro e Santana (1999), que estudaram a mineralogia de solos da Amazônia.

A caulinita foi identificada por meio dos picos 0,718 e $0,359 \mathrm{~nm}$, para todos os solos estudados, os quais colapsaram quando aquecidos à temperatura de $550{ }^{\circ} \mathrm{C}$ (Figuras 2, 3, 4 e 5). A gibbsita foi evidenciada em dois picos para o P1, com intensidade de
0,485 e 0,438 nm, enquanto nos demais perfis (P2, P3 e P4) foi observada apenas uma intensidade de pico, variando entre 0,484 a 0,491 nm. Para Horbe e Costa (1997), essa mineralogia se repete na grande maioria dos solos bem drenados da região amazônica brasileira, e é reflexo da pobreza do material de origem, das boas condições de drenagem e do maior tempo de exposição dos sedimentos aos agentes bioclimáticos.

Vale uma ressalva em relação à presença de goethita nos perfis $\mathrm{P} 1 \mathrm{e}$ P4, fato que se deve, provavelmente, à não eficácia dos tratamentos de desferrificação. 


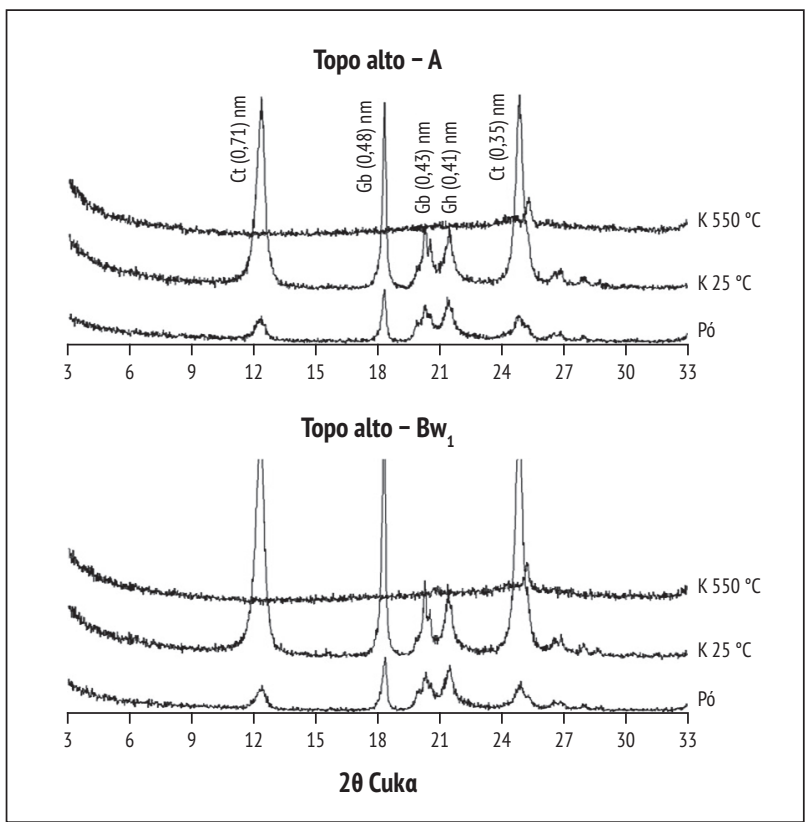

Figura 2 - Difratogramas de raios X da fração argila (pó e desferrificada) dos horizontes $\mathrm{A}_{1}$ e $\mathrm{Bt}_{1}$ do argissolo vermelho-amarelo eutrófico abrúptico, submetida a diferentes tratamentos

Legenda: $\mathrm{Ct}$ = caulinita; $\mathrm{Gb}=$ gibbsita; $\mathrm{Gh}$ = goethita.

Fonte: Dados da pesquisa.

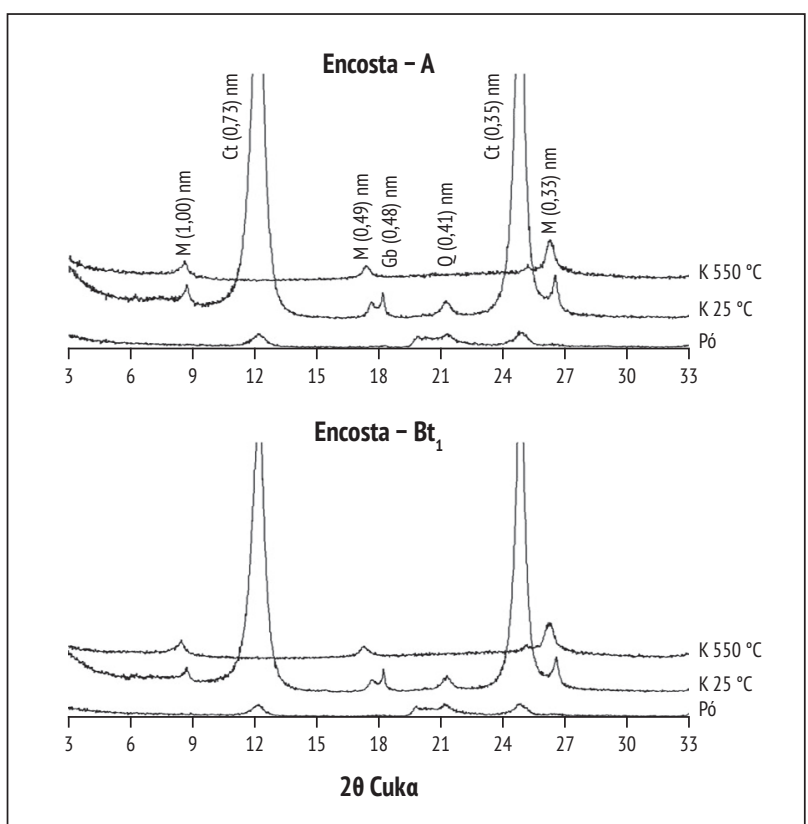

Figura 3 - Difratogramas de raios X da fração argila (pó e desferrificada) dos horizontes $\mathrm{A}_{1}$ e Bt do argissolo acinzentado eutrófico típico, submetida a diferentes tratamentos

Legenda: $\mathrm{Ct}$ = caulinita; $\mathrm{Gb}=$ gibbsita; $\mathrm{Gh}$ = goethita.

Fonte: Dados da pesquisa.

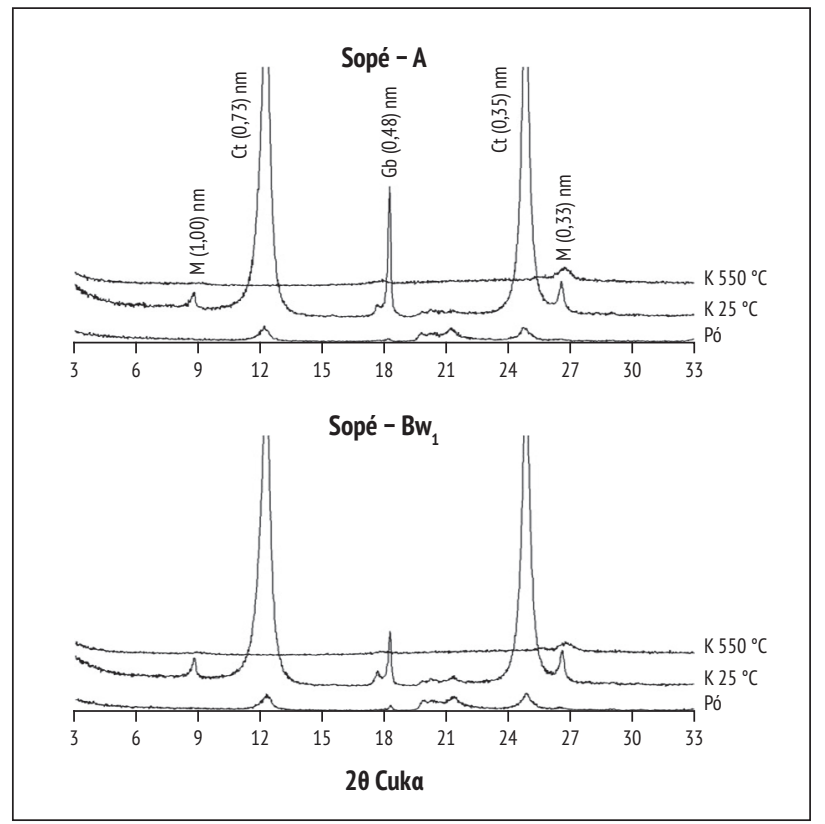

Figura 4 - Difratogramas de raios X da fração argila (pó e desferrificada) dos horizontes $\mathrm{A}_{1}$ e $\mathrm{Bt}_{1}$ do argissolo vermelho-amarelo eutrófico abrúptico, submetida a diferentes tratamentos

Legenda: $\mathrm{Ct}$ = caulinita; $\mathrm{Gb}$ = gibbsita; $\mathrm{Gh}=$ goethita.

Fonte: Dados da pesquisa.

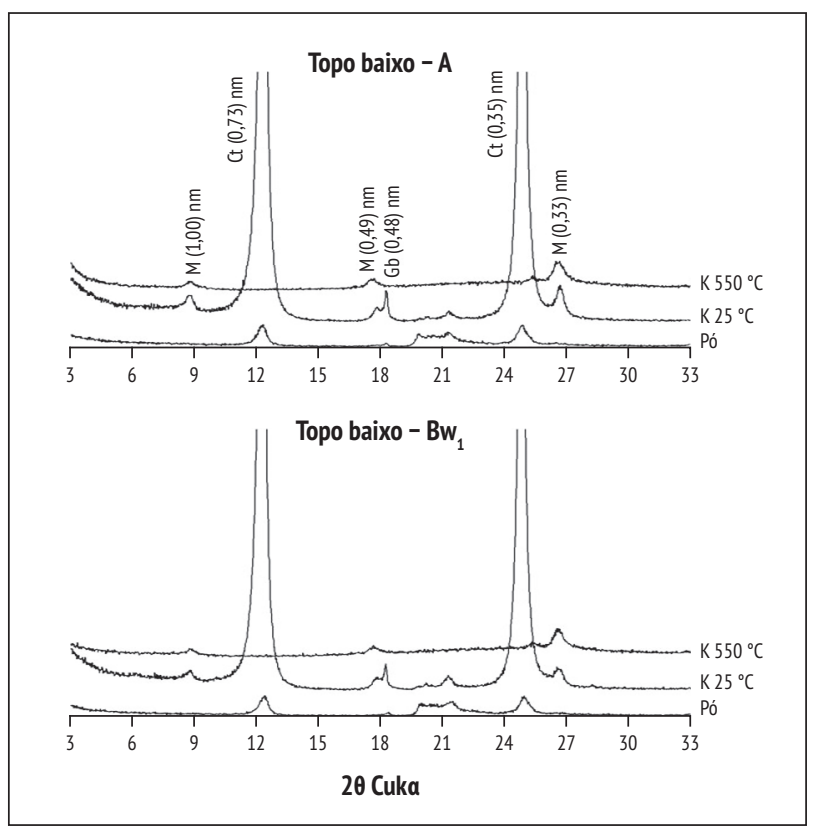

Figura 5 - Difratogramas de raios X da fração argila (pó e desferrificada) dos horizontes $\mathrm{A}_{1}$ e $\mathrm{Bt}_{1}$ do argissolo amarelo eutrófico típico, submetida a diferentes tratamentos

Legenda: $\mathrm{Ct}=$ caulinita; $\mathrm{Gb}$ = gibbsita; $\mathrm{Gh}=$ goethita.

Fonte: Dados da pesquisa. 
Os resultados da mineralogia da fração areia dos perfis P5, P6, P7, P8 são apresentados na Tabela 2, observou-se que o quartzo predomina em todos os horizontes dos solos estudados. Além dos reflexos quartzo, verificou-se no segmento de topo alto (LVd) a presença de pequenos picos de hematita e gibbsita nos horizontes $\mathrm{A}$ e $\mathrm{Bw}_{1}$, assim como presença de feldspatos e ilmenita. No segmento de topo baixo (LVAd), verificou-se a presença de hematita para os dois horizontes diagnóstico estudados $\left(\mathrm{A}\right.$ e $\left.\mathrm{Bw}_{1}\right)$ e de gibbsita e anatásio no horizonte $\mathrm{Bw}_{1}$.

Segundo Ferreira et al. (2003), a presença dos óxidos de ferro (hematita) e do hidróxido de alumínio (gibbsita), assim como dos óxidos de titânio (ilmenita), é comum em solos de ambientes tropicais, em razão das condições de intensa lixiviação. Alguns desses óxidos podem ter dominância quantitativamente importante no pedossistema, conforme a litologia dominante no material de origem e os mecanismos de pedogênese.

A fração silte apresentou uma assembleia mineralógica mais complexa que a fração areia, exibindo outros minerais além do quartzo, podendo-se destacar: gibbsita, caulinita, hematita, anatásio, ilmenita e feldspatos para todos os segmentos de vertente (Tabela 2). Além disso, foi observada, no segmento de sopé da paisagem, a presença de mica, favorecida pela maior instabilidade do ambiente, podendo ser originada a partir de sedimentos translocados, com posterior neoformação (MELO et al., 2006).

A composição mineralógica da fração argila mostrou-se relativamente homogênea (Figuras 6, 7, 8, 9), com predominância de caulinita e gibbsita, menor proporção de mica e pouca goethita e quartzo. De acordo com Marques et al. (2002), a mineralogia mais residual é característica dos ambientes amazônicos, graças principalmente à pobreza do material de origem, excelentes condições de drenagem e maior ação do intemperismo sobre os sedimentos.

Ainda em relação à mineralogia da fração argila dos solos dos perfis estudados (P5, P6, P7 e P8), verificou-se que, entre os segmentos de vertente, apenas o topo alto não apresentou presença de picos de mica, diferindo, assim, dos demais segmentos (encosta, sopé de transporte e topo baixo). Esse fato está, possivelmente, associado à maior estabilidade desse ambiente e, consequentemente, com a maior ação do intemperismo. De acordo com Lima et al. (2006), as condições de drenagem favorável, resultantes das características ambientais e da permeabilidade dos materiais de origem, levam a um processo de intemperismo acentuado, o que resulta em perfis mais profundos e de menor riqueza em minerais primários.

Tabela 2 - Composição mineralógica das frações areia e silte dos horizontes diagnósticos superficiais e subsuperficiais em diferentes segmentos de vertente em Manicoré, AM

\begin{tabular}{|c|c|c|c|c|}
\hline Segmentos de vertente & Horizonte & Profundidade (cm) & Areia & Silte \\
\hline \multicolumn{5}{|c|}{ P5 - Latossolo vermelho distrófico típico } \\
\hline \multirow[t]{2}{*}{ Topo alto } & A & $0-16$ & Gb, Hm e 0 & $\mathrm{Ct}, \mathrm{Gb}, \mathrm{Q}, \mathrm{Gh}, \mathrm{An}, \mathrm{Fd}$ e Im \\
\hline & $\mathrm{Bw}_{1}$ & $67-120$ & $\mathrm{~Gb}, \mathrm{Hm}, \mathrm{Q}, \mathrm{Fd}$ e Im & $\mathrm{Ct}, \mathrm{Gb}, \mathrm{Q}, \mathrm{Gh}, \mathrm{An}, \mathrm{Fd}$ e Im \\
\hline \multicolumn{5}{|c|}{ P6 - Argissolo vermelho-amarelo distrófico abrúptico } \\
\hline \multirow[t]{2}{*}{ Encosta } & $A$ & $0-28$ & $\underline{\mathrm{e} \mathrm{Hm}}$ & $\mathrm{Ct}, \mathrm{Gb}, \mathrm{O}, \mathrm{Gh}, \mathrm{An}, \mathrm{Fd}$ e Im \\
\hline & $\mathrm{Bt}_{1}$ & $57-82$ & Q e Im & $\mathrm{Ct}, \mathrm{Gb}, \mathrm{Q}, \mathrm{Gh}, \mathrm{An}, \mathrm{Fd}$ e Im \\
\hline \multicolumn{5}{|c|}{ P7 - Latossolo vermelho-amarelo eutrófico típico } \\
\hline \multirow[t]{2}{*}{ Sopé } & A & $0-18$ & 0 & $\mathrm{M}, \mathrm{Ct}, \mathrm{Gb}, \mathrm{O}, \mathrm{Gh}$ e Im \\
\hline & $\mathrm{Bw}_{1}$ & $42-71$ & $\underline{0}$ & $\mathrm{M}, \mathrm{Ct}, \mathrm{Gb}, \mathrm{O}, \mathrm{Gh}, \mathrm{Fd}$ e Im \\
\hline \multicolumn{5}{|c|}{ P8 - Latossolo vermelho-amarelo distrófico típico } \\
\hline \multirow[t]{2}{*}{ Topo baixo } & A & $0-22$ & Q e Hm & $\mathrm{Ct}, \mathrm{Gb}, \mathrm{Q}, \mathrm{Gh}, \mathrm{An}, \mathrm{Fd}$ e Im \\
\hline & $\mathrm{Bw}_{1}$ & $47-77$ & Q, Hm, Gb e An & $\mathrm{Ct}, \mathrm{Gb}, \mathrm{O}, \mathrm{Gh}, \mathrm{An}, \mathrm{Fd}$ e Im \\
\hline
\end{tabular}

Legenda: $\mathrm{Q}=$ quartzo; $\mathrm{Gb}=$ gibbsita; $\mathrm{Ct}$ = caulinita; $\mathrm{Hm}=$ hematita; $\mathrm{An}=$ anatásio; $\mathrm{Im}=$ ilmenita; $\mathrm{Fd}$ = feldspatos; $\mathrm{M}$ = mica. Fonte: Dados da pesquisa. 


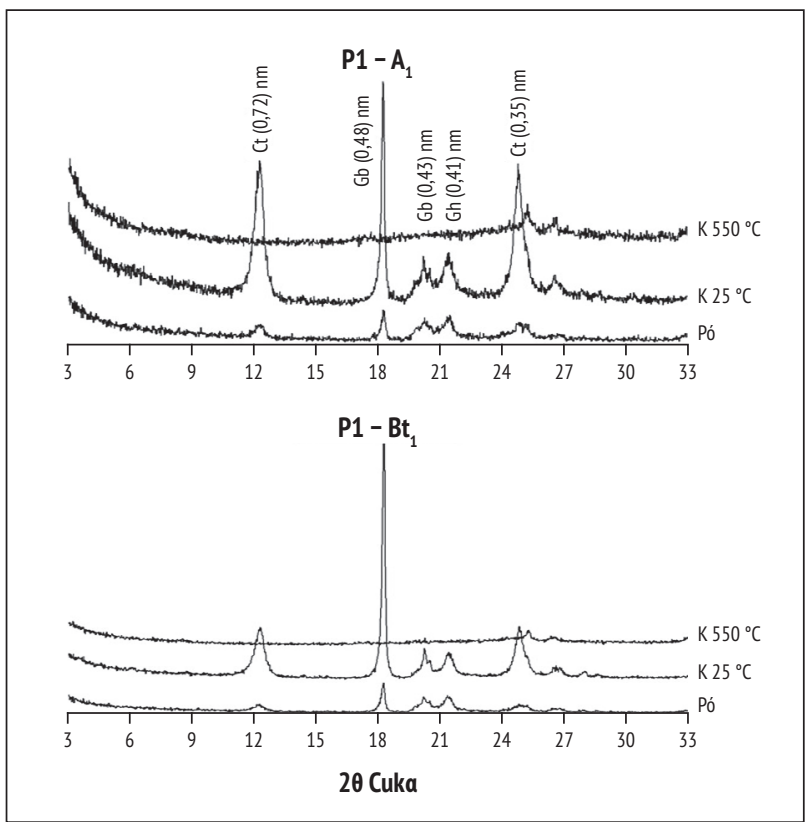

Figura 6 - Difratogramas de raios X da fração argila (desferrificada e pó) dos horizontes superficiais e subsuperficiais no topo alto, submetida a diferentes tratamentos

Legenda: $\mathrm{Gb}$ = gibbsita; $\mathrm{Ct}$ = caulinita; $\mathrm{Gh}$ = goethita.

Fonte: Dados da pesquisa.

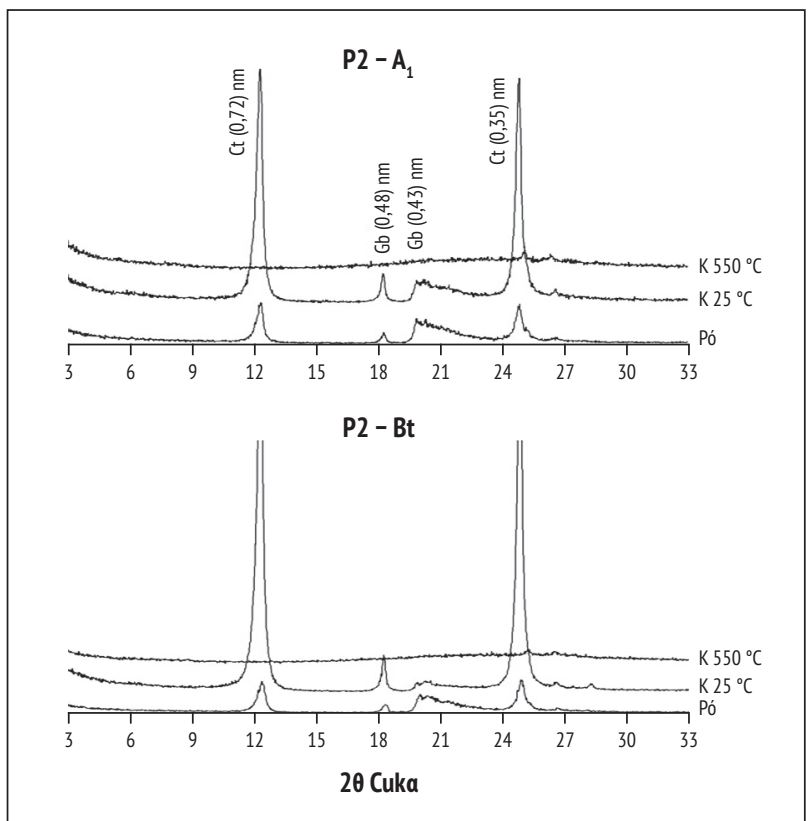

Figura 7 - Difratogramas de raios X da fração argila (desferrificada e pó) dos horizontes superficiais e subsuperficiais na encosta, submetida a diferentes tratamentos

Legenda: $\mathrm{M}=$ mica; $\mathbf{Q}=$ quartzo; $\mathrm{Gb}=$ gibbsita; $\mathrm{Ct}=$ caulinita. Fonte: Dados da pesquisa.

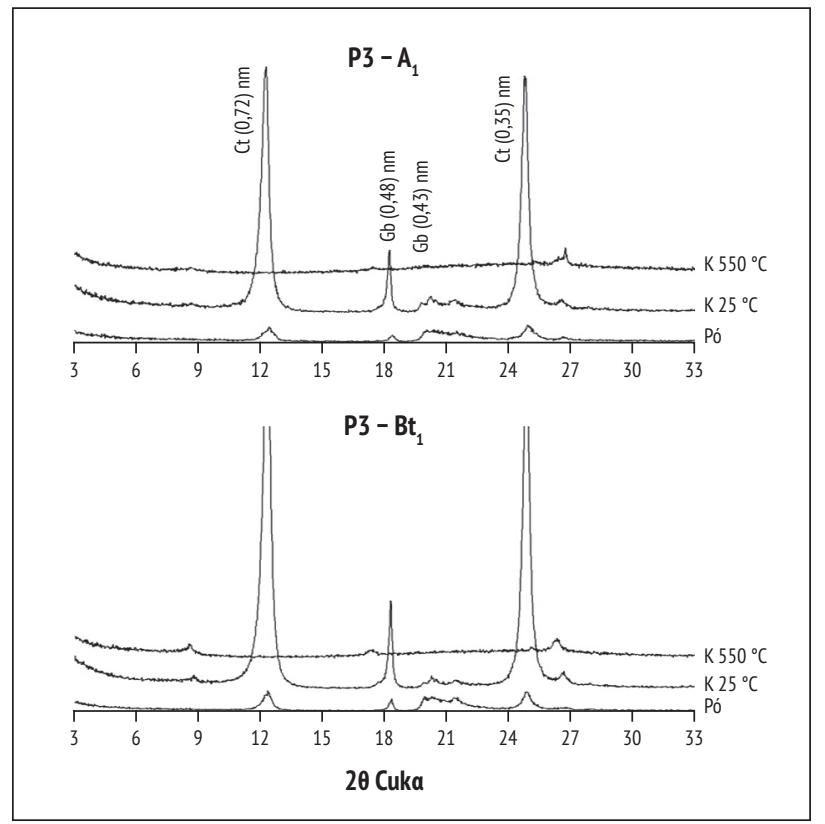

Figura 8 - Difratogramas de raios X da fração argila (desferrificada e pó) dos horizontes superficiais e subsuperficiais no sopé, submetida a diferentes tratamentos

Legenda: $M$ = mica; $G b$ = gibbsita; $C t$ = caulinita.

Fonte: Dados da pesquisa.

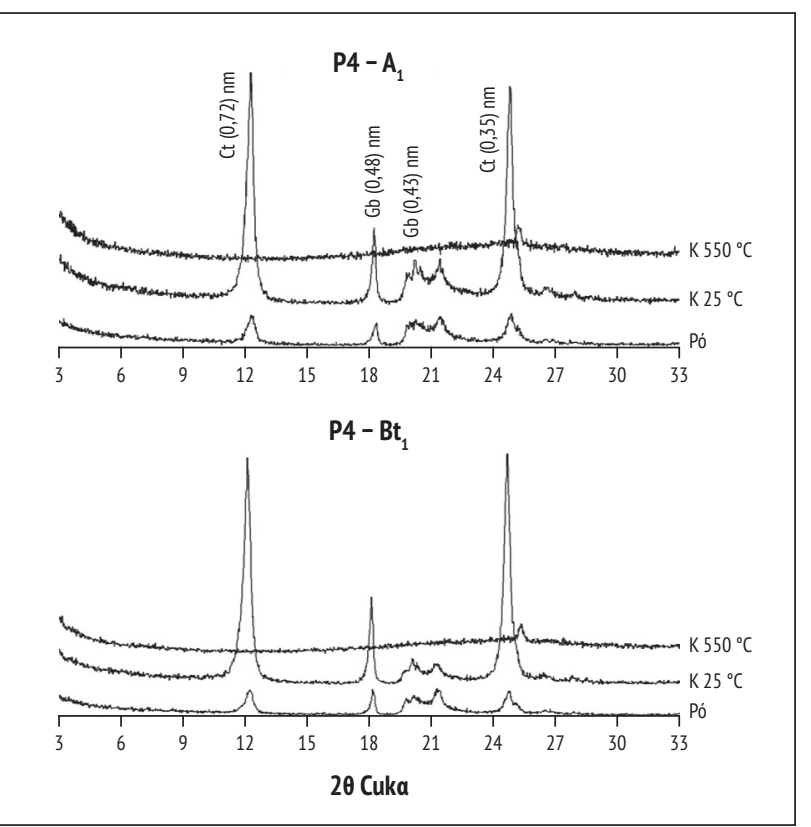

Figura 9 - Difratogramas de raios X da fração argila (desferrificada e pó) dos horizontes superficiais e subsuperficiais no topo baixo, submetida a diferentes tratamentos

Legenda: $\mathrm{M}=$ mica; $\mathrm{Gb}=$ gibbsita; $\mathrm{Ct}$ = caulinita.

Fonte: Dados da pesquisa. 


\section{Conclusões}

Os argissolos apresentaram fração argila com dominância de caulinita, gibbsita e traços de mica; os latossolos exibiram mineralogia da fração argila relativamente homogênea, com predominância de caulinita e gibbsita e menor proporção de mica e quartzo.

\section{Referências}

BRASIL. Ministério das Minas e Energia. Projeto Radambrasil, folha SB. 20, Purus. Rio de Janeiro: Departamento Nacional da Produção Mineral, 1978.

COUCEIRO, P. R. C.; SANTANA, G. P. Caulinita em solo da Amazônia: caracterização e permutabilidade. Acta Amazonica, v. 29, p. 267-275,1999.

CENTRO DE PESQUISA DE RECURSOS MINERAIS - CPRM. Hidroclimatologia, geologia, recursos minerais, geomorfologia e unidades de paisagens. Relatório Técnico, Manaus, p. 93, 2001.

DALRYMPLE, J. B.; BLONG, R. J.; CONACHER, A. J. A hypothetical nine unit land a surface model. Z. Geomorphology, v. 12 , n. 1, p. 60-76, 1968.

EMPRESA BRASILEIRA DE PESQUISA AGROPECUÁRIA EMBRAPA. Centro Nacional de Pesquisa de Solos. Sistema Brasileiro de Classificação de Solos. Brasília: EMBRAPA, 2006.

FERREIRA, B. A. et al. Óxidos de ferro das frações areia e silte de um nitossolo desenvolvido de basalto. Revista Brasileira de Ciência do Solo, v. 27, n. 3, p. 405-413, 2003.

GAMA, J. R. V. et al. Comparação entre florestas de várzea e de terra firme do Estado do Pará. Revista Árvore, v. 29, n. 4, p. 607-616, 2005.

GLASER, B. Prehistorically modified soils of central Amazonia: a model for sustainable agriculture in the twentyfirst century. Philosophical Transactions the Royal Society B, v. 362, n. 1478, p. 187-196, 2007.

HORBE, A. M. C.; COSTA, M. L. Solos gerados a partir do intemperismo de crostas lateríticas sílicoferruginosas. Acta Amazonica, v. 27, p. 241-256, 1997.
KÄMPF, N.; KERN, D. C. O solo como registro da ocupação humana pré-histórica na Amazônia. In: VIDAL-TORRADO, P. et al. (Org.). Tópicos em ciência do solo. Viçosa: Sociedade Brasileira de Ciência do Solo, 2005. v. 5, p. 277-320.

KERN, D. C.; KÄMPF, N. O efeito de antigos assentamentos indígenas na formação de solos com terra preta arqueológica na região de Oriximiná - PA. Revista Brasileira de Ciência do Solo, v. 13, p. 219-225, 1989.

LIMA, H. N. Gênese, química, mineralogia e micromorfologia de solos da Amazônia Ocidental. Viçosa, 2001. 176 f. Tese (Doutorado em Solos e Nutrição de Plantas) Universidade Federal de Viçosa, Viçosa, 2001.

LIMA, H. N. et al. Mineralogia e química de três solos de uma toposseqüência da Bacia Sedimentar do Alto Solimões, Amazônia Ocidental. Revista Brasileira de Ciência do Solo, v. 30, n. 1, p. 59-68, 2006.

MARQUES, J. J. G. S. M. et al. Mineralogy of soils with unusually high exchangeable $\mathrm{Al}$ from the western Amazon Region. Clay Mineralogy, v. 37, p. 651-661, 2002.

MARTINS, G. C. et al. Campos nativos e matas adjacentes da região de Humaitá (AM): atributos diferenciais dos solos. Ciência e Agrotecnologia, v. 30, p. 221-227, 2006.

MELO, V. F. et al. Caracterização física, química e mineralógica de solos da colônia agrícola do Apiaú (Roraima, Amazônia), sob diferentes usos e após queima. Revista Brasileira de Ciência do Solo, v. 30, p. 1039-1050, 2006.

SANTOS, R. D. et al. Manual de descrição e coleta de solos no campo. 5. ed. Viçosa: Sociedade Brasileira de Ciência do Solo, 2005.

ZONEAMENTO ECOLÓGICO ECONÔMICO DO SUL-SUDESTE DO AMAZONAS - ZEE, AM. Zoneamento Ecológico Econômico do Sul-Sudeste do Amazonas. Manaus: IPAAM, 2008.
Recebido: 01/08/2010 Received: 08/01/2010

Aprovado: 01/09/2010 Approved: 09/01/2010 